\title{
A generalization on weak contractions in partially ordered $b$-metric spaces and its application to quadratic integral equations
}

\author{
Reza Allahyari ${ }^{1}$, Reza Arab ${ }^{2 *}$ and Ali Shole Haghighi ${ }^{3}$
}

\section{"Correspondence:}

mathreza.arab@iausari.ac.ir

${ }^{2}$ Department of Mathematics, Sari

Branch, Islamic Azad University, Sari, Iran

Full list of author information is

available at the end of the article

\begin{abstract}
We introduce the notion of almost generalized $(\psi, \varphi, L)$-contractive mappings, and establish the coincidence and common fixed point results for this class of mappings in partially ordered complete $b$-metric spaces. Our results extend and improve several known results from the context of ordered metric spaces to the setting of ordered $b$-metric spaces. As an application, we prove the existence of a unique solution to a class of nonlinear quadratic integral equations.
\end{abstract}

Keywords: fixed point; common fixed point; coincidence point; integral equations; $b$-metric space; partially ordered set

\section{Introduction}

Fixed points theorems in partially ordered metric spaces were firstly obtained in 2004 by Ran and Reurings [1], and then by Nieto and Rodríguez-López [2]. In this direction several authors obtained further results under weak contractive conditions (see, e.g., [3-8]). Berinde initiated in [9] the concept of almost contractions and obtained several interesting fixed point theorems. This has been a subject of intense study since then; see, e.g., [10-20]. Some authors used related notions as 'condition (B)' (Babu et al. [21]) and 'almost generalized contractive condition' for two maps (Ćirić et al. [22]), and for four maps (Aghajani et $a l$. [23]). See also a note by Pacurar [15]. On the other hand, the concept of $b$-metric space was introduced by Czerwik in [24]. After that, several interesting results of the existence of fixed point for single-valued and multivalued operators in $b$-metric spaces have been obtained (see [25-40]). Pacurar [41] proved some results on sequences of almost contractions and fixed points in $b$-metric spaces. Recently, Hussain and Shah [42] obtained results on KKM mappings in cone $b$-metric spaces. Using the concepts of partially ordered metric spaces, almost generalized contractive condition, and $b$-metric spaces, we define a new concept of almost generalized $(\psi, \varphi, L)$-contractive condition. In this paper, some coincidence and common fixed point theorems for mappings satisfying almost generalized $(\psi, \varphi, L)$-contractive condition in the setup of partially ordered complete $b$-metric spaces are proved. Consistent with [43] and [40, p.264], the following definitions and results will be needed in the sequel. 
Definition 1.1 [43] Let $X$ be a (nonempty) set and $s \geq 1$ be a given real number. A function $d: X \times X \rightarrow \mathbb{R}^{+}$is said to be a $b$-metric space iff for all $x, y, z \in X$, the following conditions are satisfied:

(i) $d(x, y)=0$ iff $x=y$,

(ii) $d(x, y)=d(y, x)$,

(iii) $d(x, y) \leq s[d(x, z)+d(z, y)]$.

The pair $(X, d)$ is called a $b$-metric space with the parameter $s$.

It should be noted that the class of $b$-metric spaces is effectively larger than that of metric spaces, since a $b$-metric is a metric, when $s=1$.

The following example shows that in general a $b$-metric does not necessarily need to be a metric (see, also, [40]).

Example 1.1 [44] Let $(X, d)$ be a metric space and $\rho(x, y)=(d(x, y))^{p}$, where $p>1$ is a real number. Then $\rho$ is a $b$-metric with $s=2^{p-1}$. However, if $(X, d)$ is a metric space, then $(X, \rho)$ is not necessarily a metric space. For example, if $X=\mathbb{R}$ is the set of real numbers and $d(x, y)=|x-y|$ is the usual Euclidean metric, then $\rho(x, y)=(x-y)^{s}$ is a $b$-metric on $\mathbb{R}$ with $s=2$, but it is not a metric on $\mathbb{R}$.

Also, the following example of a $b$-metric space is given in [45].

Example 1.2 [45] Let $X$ be the set of Lebesgue measurable functions on $[0,1]$ such that $\int_{0}^{1}|f(x)|^{2} d x<\infty$. Define $D: X \times X \rightarrow[0, \infty)$ by $D(f, g)=\int_{0}^{1}|f(x)-g(x)|^{2} d x$. As $\left(\int_{0}^{1} \mid f(x)-\right.$ $\left.\left.g(x)\right|^{2} d x\right)^{\frac{1}{2}}$ is a metric on $X$, then, from the previous example, $D$ is a $b$-metric on $X$, with $s=2$, where the $b$-metric $D$ is defined with $D(x, y)=\|d(x, y)\|, d$ is a cone metric (also see [46-49]).

Khamsi [50] also showed that each cone metric space over a normal cone has a $b$-metric structure.

Definition 1.2 [6] We shall say that the mapping $T$ is $g$-nondecreasing if

$$
g x \leq g y \quad \Longrightarrow \quad T x \leq T y .
$$

\section{Main results}

Throughout the paper, let $\Psi$ be the family of all functions $\psi:[0, \infty) \rightarrow[0, \infty)$ satisfying the following conditions:

(a) $\psi$ is continuous,

(b) $\psi$ is nondecreasing,

(c) $\psi(0)=0<\psi(t)$ for every $t>0$.

We denote by $\Phi$ the set of all functions $\varphi:[0, \infty) \rightarrow[0, \infty)$ satisfying the following conditions:

(i) $\varphi$ is right continuous,

(ii) $\varphi$ is nondecreasing,

(iii) $\varphi(t)<t$ for every $t>0$.

Let $(X, d, \leq)$ be a partially ordered $b$-metric space and $T: X \rightarrow X$ and $g: X \rightarrow X$ be two mappings. Set

$$
M(x, y)=\max \left\{d(g x, g y), d(g x, T x), d(g y, T y), \frac{d(g x, T y)+d(g y, T x)}{2 s}\right\}
$$


and

$$
N(x, y)=\min \{d(g x, T x), d(g y, T y), d(g x, T y), d(g y, T x)\}
$$

Now, we introduce the following definition.

Definition 2.1 Let $(X, d, \leq)$ be a partially ordered $b$-metric space. We say that $T: X \rightarrow X$ is an almost generalized $(\psi, \varphi, L)$-contractive mapping with respect to $g: X \rightarrow X$ for some $\psi \in \Psi, \varphi \in \Phi$, and $L \geq 0$ if

$$
\psi\left(s^{3} d(T x, T y)\right) \leq \varphi(\psi(M(x, y)))+L \psi(N(x, y))
$$

for all $x, y \in X$ with $g x \leq g y$.

Now, we establish some results for the existence of coincidence point and common fixed point of mappings satisfying almost generalized $(\psi, \varphi, L)$-contractive condition in the setup of partially ordered $b$-metric spaces. The first result in this paper is the following coincidence point theorem.

Theorem 2.1 Suppose that $(X, d, \leq)$ is a partially ordered complete b-metric space. Let $T$ : $X \rightarrow X$ be an almost generalized $(\psi, \varphi, L)$-contractive mapping with respect to $g: X \rightarrow X$, and $T$ and $g$ are continuous such that $T$ is a monotone $g$-nondecreasing mapping, commutative with $g$ and $T(X) \subseteq g(X)$. If there exists $x_{0} \in X$ such that $g x_{0} \leq T x_{0}$, then $T$ and $g$ have a coincidence point in $X$.

Proof By the given assumptions, there exists $x_{0} \in X$ such that $g x_{0} \leq T x_{0}$. Since $T(X) \subseteq$ $g(X)$, we can define $x_{1} \in X$ such that $g x_{1}=T x_{0}$, then $g x_{0} \leq T x_{0}=g x_{1}$. Also there exists $x_{2} \in X$ such that $g x_{2}=T x_{1}$. Since $T$ is a monotone $g$-nondecreasing mapping, we have

$$
g x_{1}=T x_{0} \leq T x_{1}=g x_{2} .
$$

Continuing in this way, we construct a sequence $\left\{x_{n}\right\}$ in $X$ such that for all $n=0,1,2, \ldots$,

$$
g x_{n+1}=T x_{n}
$$

for which

$$
g x_{0} \leq g x_{1} \leq g x_{2} \leq \cdots \leq g x_{n} \leq g x_{n+1} \leq \cdots
$$

If there exists $k_{0} \in \mathbb{N}$ such that $g x_{k_{0}+1}=g x_{k_{0}}$, then $g x_{k_{0}}=T x_{k_{0}}$. This means that $x_{k_{0}}$ is a coincidence point of $T, g$, and the proof is finished. Thus, $g x_{n+1} \neq g x_{n}$ for all $n \in \mathbb{N}$. From (2.2) and (2.3) and the inequality (2.1) with $(x, y)=\left(x_{n}, x_{n+1}\right)$, we have

$$
\begin{aligned}
\psi\left(d\left(g x_{n+1}, g x_{n+2}\right)\right) & \leq \psi\left(s^{3} d\left(g x_{n+1}, g x_{n+2}\right)\right)=\psi\left(s^{3} d\left(T x_{n}, T x_{n+1}\right)\right) \\
& \leq \varphi\left(\psi\left(M\left(x_{n}, x_{n+1}\right)\right)\right)+L \psi\left(N\left(x_{n}, x_{n+1}\right)\right)
\end{aligned}
$$


where

$$
\begin{aligned}
M\left(x_{n}, x_{n+1}\right)= & \max \left\{d\left(g x_{n}, g x_{n+1}\right), d\left(g x_{n}, T x_{n}\right), d\left(g x_{n+1}, T x_{n+1}\right),\right. \\
& \left.\frac{d\left(g x_{n}, T x_{n+1}\right)+d\left(g x_{n+1}, T x_{n}\right)}{2 s}\right\} \\
= & \max \left\{d\left(g x_{n}, g x_{n+1}\right), d\left(g x_{n}, g x_{n+1}\right), d\left(g x_{n+1}, g x_{n+2}\right), \frac{d\left(g x_{n}, g x_{n+2}\right)}{2 s}\right\}
\end{aligned}
$$

and

$$
N\left(x_{n}, x_{n+1}\right)=\min \left\{d\left(g x_{n}, T x_{n}\right), d\left(g x_{n+1}, T x_{n+1}\right), d\left(g x_{n}, T x_{n+1}\right), d\left(g x_{n+1}, T x_{n}\right)\right\}=0 .
$$

Since

$$
\frac{d\left(g x_{n}, g x_{n+2}\right)}{2 s} \leq \frac{d\left(g x_{n}, g x_{n+1}\right)+d\left(g x_{n+1}, g x_{n+2}\right)}{2} \leq \max \left\{d\left(g x_{n}, g x_{n+1}\right), d\left(g x_{n+1}, g x_{n+2}\right)\right\},
$$

then we get

$$
\begin{aligned}
& M\left(x_{n}, x_{n+1}\right)=\max \left\{d\left(g x_{n}, g x_{n+1}\right), d\left(g x_{n+1}, g x_{n+2}\right)\right\}, \\
& N\left(x_{n}, x_{n+1}\right)=0 .
\end{aligned}
$$

By (2.4) and (2.5), we have

$$
\psi\left(d\left(g x_{n+1}, g x_{n+2}\right)\right) \leq \varphi\left(\psi\left(\max \left\{d\left(g x_{n}, g x_{n+1}\right), d\left(g x_{n+1}, g x_{n+2}\right)\right\}\right)\right) .
$$

Suppose that $\max \left\{d\left(g x_{n}, g x_{n+1}\right), d\left(g x_{n+1}, g x_{n+2}\right)\right\}=d\left(g x_{n+1}, g x_{n+2}\right)>0$ for some $n \in \mathbb{N}$, then by $(2.6)$

$$
\psi\left(d\left(g x_{n+1}, g x_{n+2}\right)\right) \leq \varphi\left(\psi\left(d\left(g x_{n+1}, g x_{n+2}\right)\right)\right)<\psi\left(d\left(g x_{n+1}, g x_{n+2}\right)\right) ;
$$

a contradiction. Hence,

$$
\max \left\{d\left(g x_{n}, g x_{n+1}\right), d\left(g x_{n+1}, g x_{n+2}\right)\right\}=d\left(g x_{n}, g x_{n+1}\right)
$$

and thus

$$
\psi\left(d\left(g x_{n+1}, g x_{n+2}\right)\right) \leq \varphi\left(\psi\left(d\left(g x_{n}, g x_{n+1}\right)\right)\right)<\psi\left(d\left(g x_{n}, g x_{n+1}\right)\right) .
$$

Thus, we get

$$
\psi\left(d\left(g x_{n+1}, g x_{n+2}\right)\right)<\psi\left(d\left(g x_{n}, g x_{n+1}\right)\right)
$$

for all $n \in \mathbb{N}$. Now, from

$$
\begin{aligned}
\psi\left(d\left(g x_{n}, g x_{n+1}\right)\right) & \leq \varphi\left(\psi\left(d\left(g x_{n-1}, g x_{n}\right)\right)\right) \leq \varphi^{2}\left(\psi\left(d\left(g x_{n-2}, g x_{n-1}\right)\right)\right) \\
& \leq \cdots \leq \varphi^{n}\left(\psi\left(d\left(g x_{0}, g x_{1}\right)\right)\right)
\end{aligned}
$$


and the property of $\varphi$, we obtain $\lim _{n \rightarrow \infty} \psi\left(d\left(g x_{n}, g x_{n+1}\right)\right)=0$, and consequently

$$
\lim _{n \rightarrow \infty} d\left(g x_{n}, g x_{n+1}\right)=0 .
$$

Now, we shall prove that $\left\{g x_{n}\right\}$ is a Cauchy sequence in $(X, d)$. Suppose, on the contrary, that $\left\{g x_{n}\right\}$ is not a Cauchy sequence. Then there exist $\epsilon>0$ and subsequences $\left\{g x_{m(k)}\right\}$, $\left\{g x_{n(k)}\right\}$ of $\left\{g x_{n}\right\}$ with $m(k)>n(k) \geq k$ such that

$$
d\left(g x_{n(k)}, g x_{m(k)}\right) \geq \epsilon .
$$

Additionally, corresponding to $n(k)$, we may choose $m(k)$ such that it is the smallest integer satisfying $(2.8)$ and $m(k)>n(k) \geq k$. Thus,

$$
d\left(g x_{n(k)}, g x_{m(k)-1}\right)<\epsilon .
$$

Using the triangle inequality in $b$-metric space and (2.8) and (2.9) we obtain

$$
\begin{aligned}
\epsilon & \leq d\left(g x_{m(k)}, g x_{n(k)}\right) \leq s d\left(g x_{m(k)}, g x_{m(k)-1}\right)+s d\left(g x_{m(k)-1}, g x_{n(k)}\right) \\
& <s d\left(g x_{m(k)}, g x_{m(k)-1}\right)+s \epsilon .
\end{aligned}
$$

Taking the upper limit as $k \rightarrow \infty$ and using (2.7) we obtain

$$
\epsilon \leq \limsup _{k \rightarrow \infty} d\left(g x_{n(k)}, g x_{m(k)}\right) \leq s \epsilon
$$

Also

$$
\begin{aligned}
\epsilon & \leq d\left(g x_{n(k)}, g x_{m(k)}\right) \leq s d\left(g x_{n(k)}, g x_{m(k)+1}\right)+s d\left(g x_{m(k)+1}, g x_{m(k)}\right) \\
& \leq s^{2} d\left(g x_{n(k)}, g x_{m(k)}\right)+s^{2} d\left(g x_{m(k)}, g x_{m(k)+1}\right)+s d\left(g x_{m(k)+1}, g x_{m(k)}\right) \\
& \leq s^{2} d\left(g x_{n(k)}, g x_{m(k)}\right)+\left(s^{2}+s\right) d\left(g x_{m(k)}, g x_{m(k)+1}\right) .
\end{aligned}
$$

So from (2.7) and (2.10), we have

$$
\frac{\epsilon}{s} \leq \limsup _{k \rightarrow \infty} d\left(g x_{n(k)}, g x_{m(k)+1}\right) \leq s^{2} \epsilon
$$

Also

$$
\begin{aligned}
\epsilon & \leq d\left(g x_{m(k)}, g x_{n(k)}\right) \leq s d\left(g x_{m(k)}, g x_{n(k)+1}\right)+s d\left(g x_{n(k)+1}, g x_{n(k)}\right) \\
& \leq s^{2} d\left(g x_{m(k)}, g x_{n(k)}\right)+s^{2} d\left(g x_{n(k)}, g x_{n(k)+1}\right)+s d\left(g x_{n(k)+1}, g x_{n(k)}\right) \\
& \leq s^{2} d\left(g x_{m(k)}, g x_{n(k)}\right)+\left(s^{2}+s\right) d\left(g x_{n(k)}, g x_{n(k)+1}\right) .
\end{aligned}
$$

So from (2.7) and (2.10), we have

$$
\frac{\epsilon}{s} \leq \limsup _{k \rightarrow \infty} d\left(g x_{m(k)}, g x_{n(k)+1}\right) \leq s^{2} \epsilon
$$


Also

$$
d\left(g x_{n(k)+1}, g x_{m(k)}\right) \leq s d\left(g x_{n(k)+1}, g x_{m(k)+1}\right)+s d\left(g x_{m(k)+1}, g x_{m(k)}\right)
$$

so from (2.7) and (2.12), we have

$$
\frac{\epsilon}{s^{2}} \leq \limsup _{k \rightarrow \infty} d\left(g x_{n(k)+1}, g x_{m(k)+1}\right)
$$

Linking (2.7), (2.10), (2.11) together with (2.12) we get

$$
\begin{aligned}
& \underset{k \rightarrow \infty}{\limsup } M\left(x_{n(k)}, x_{m(k)}\right) \\
&=\max \left\{\limsup _{k \rightarrow \infty} d\left(g x_{n(k)}, g x_{m(k)}\right), \limsup _{k \rightarrow \infty} d\left(g x_{n(k)}, g x_{n(k)+1}\right), \limsup _{k \rightarrow \infty} d\left(g x_{m(k)}, g x_{m(k)+1}\right),\right. \\
&\left.\frac{\lim \sup _{k \rightarrow \infty} d\left(g x_{n(k)}, g x_{m(k)+1}\right)+\limsup _{k \rightarrow \infty} d\left(g x_{m(k)}, g x_{n(k)+1}\right)}{2 s}\right\} \\
& \leq \max \left\{s \epsilon, 0,0, \frac{s^{2} \epsilon+s^{2} \epsilon}{2 s}\right\}=s \epsilon
\end{aligned}
$$

So,

$$
\limsup M\left(x_{n(k)}, x_{m(k)}\right) \leq \epsilon s .
$$

Similarly, we have

$$
\limsup _{k \rightarrow \infty} N\left(x_{n(k)}, x_{m(k)}\right)=0
$$

Since $m(k)>n(k)$ from (2.2), we have

$$
g x_{n(k)} \leq g x_{m(k)}
$$

Thus,

$$
\begin{aligned}
\psi\left(s^{3} d\left(g x_{n(k)+1}, g x_{m(k)+1}\right)\right) & =\psi\left(s^{3} d\left(T x_{n(k)}, T x_{m(k)}\right)\right) \\
& \leq \varphi\left(\psi\left(M\left(x_{n(k)}, x_{m(k)}\right)\right)\right)+L \psi\left(N\left(x_{n(k)}, x_{m(k)}\right)\right) .
\end{aligned}
$$

Passing to the upper limit as $k \rightarrow \infty$, and using (2.13), (2.14), and (2.15), we get

$$
\begin{aligned}
\psi(s \epsilon) & \leq \psi\left(s^{3} \limsup _{k \rightarrow \infty} d\left(g x_{n(k)+1}, g x_{m(k)+1}\right)\right)=\limsup _{k \rightarrow \infty} \psi\left(s^{3} d\left(g x_{n(k)+1}, g x_{m(k)+1}\right)\right) \\
& =\limsup _{k \rightarrow \infty} \psi\left(s^{3} d\left(T x_{n(k)}, T x_{m(k)}\right)\right) \\
& \leq \limsup _{k \rightarrow \infty} \varphi\left(\psi\left(M\left(x_{n(k)}, x_{m(k)}\right)\right)\right)+\underset{k \rightarrow \infty}{\limsup L \psi\left(N\left(x_{n(k)}, x_{m(k)}\right)\right)} \\
& =\varphi\left(\psi\left(\limsup _{k \rightarrow \infty} M\left(x_{n(k)}, x_{m(k)}\right)\right)\right)+L \psi\left(\limsup _{k \rightarrow \infty} N\left(x_{n(k)}, x_{m(k)}\right)\right) \\
& \leq \varphi(\psi(\epsilon s))<\psi(s \epsilon),
\end{aligned}
$$


which is a contradiction. Thus, we proved that $\left\{g x_{n}\right\}$ is a Cauchy sequence in $(X, d)$. Since $X$ is a complete $b$-metric space, there exists $x \in X$ such that

$$
\lim _{n \rightarrow \infty} g x_{n+1}=x
$$

From the commutativity of $T$ and $g$, we have

$$
g\left(g x_{n+1}\right)=g\left(T\left(x_{n}\right)\right)=T\left(g x_{n}\right) .
$$

Letting $n \rightarrow \infty$ in (2.17) and from the continuity of $T$ and $g$, we get

$$
g x=\lim _{n \rightarrow \infty} g\left(g x_{n+1}\right)=\lim _{n \rightarrow \infty} T\left(g x_{n}\right)=T\left(\lim _{n \rightarrow \infty} g x_{n}\right)=T(x) .
$$

This implies that $x$ is a coincidence point of $T$ and $g$. This completes the proof.

Now, we will prove the following result.

Theorem 2.2 Suppose that $(X, d, \leq)$ is a partially ordered complete b-metric space. Let $T: X \rightarrow X$ be an almost generalized $(\psi, \varphi, L)$-contractive mapping with respect to $g: X \rightarrow$ $X, T$ is a $g$-nondecreasing mapping and $T(X) \subseteq g(X)$. Also suppose

$$
\begin{aligned}
& \text { if }\left\{g x_{n}\right\} \subset X \text { is a nondecreasing sequence with } g x_{n} \rightarrow g z \text { in } g X, \\
& \text { then } g x_{n} \leq g z, g z \leq g(g z) \forall n \text { hold. }
\end{aligned}
$$

Also suppose $g X$ is closed. If there exists $x_{0} \in X$ such that $g x_{0} \leq T x_{0}$, then $T$ and $g$ have a coincidence. Further, if $T$ and $g$ commute at their coincidence points, then $T$ and $g$ have $a$ common fixed point.

Proof As in the proof of Theorem 2.1, we can show that $\left\{g x_{n}\right\}$ is a Cauchy sequence. Since $g X$ is a closed, there exists $x \in X$ such that

$$
\lim _{n \rightarrow \infty} g x_{n+1}=g x .
$$

Now we show that $x$ is a coincidence point of $T$ and $g$. Since from (2.18) and (2.19) we have $g x_{n} \leq g x$ for all $n$, then by the triangle inequality in a $b$-metric space and (2.1), we get

$$
\begin{aligned}
& d(g x, T x) \leq s d\left(g x, g x_{n+1}\right)+s d\left(g x_{n+1}, T x\right)=s d\left(g x, g x_{n+1}\right)+s d\left(T x_{n}, T x\right), \\
& \begin{aligned}
\psi(d(g x, T x)) \leq & \lim _{n \rightarrow \infty} \psi\left(s d\left(T x_{n}, T x\right)\right) \leq \lim _{n \rightarrow \infty} \psi\left(s^{3} d\left(T x_{n}, T x\right)\right) \\
& \leq \lim _{n \rightarrow \infty}\left[\varphi\left(\psi\left(M\left(x_{n}, x\right)\right)\right)+L \psi\left(N\left(x_{n}, x\right)\right)\right] \\
& \leq \varphi(\psi(d(g x, T x)))<\psi(d(g x, T x)) .
\end{aligned}
\end{aligned}
$$

Indeed,

$$
\begin{aligned}
\lim _{n \rightarrow \infty} M\left(x_{n}, x\right) & =\lim _{n \rightarrow \infty} \max \left\{d\left(g x_{n}, g x\right), d\left(g x_{n}, T x_{n}\right), d(g x, T x), \frac{d\left(g x_{n}, T x\right)+d\left(g x, T x_{n}\right)}{2 s}\right\} \\
& =d(g x, T x)
\end{aligned}
$$


and

$$
\lim _{n \rightarrow \infty} N\left(x_{n}, x\right)=\lim _{n \rightarrow \infty} \min \left\{d\left(g x_{n}, T x_{n}\right), d(g x, T x), d\left(g x_{n}, T x\right), d\left(g x, T x_{n}\right)\right\}=0 .
$$

Hence $d(g x, T x)=0$, that is, $T x=g x$. Thus we proved that $T$ and $g$ have a coincidence. Suppose now that $T$ and $g$ commute at $x$. Set $y=T x=g x$. Then

$$
T y=T(g x)=g(T x)=g y .
$$

Since from (2.18) we have $g x \leq g(g x)=g y$ and as $g x=T x$ and $g y=T y$, from (2.1) we obtain

$$
\begin{aligned}
\psi(d(T x, T y)) \leq & \psi\left(s^{3} d(T x, T y)\right) \leq \varphi(\psi(M(x, y)))+L \psi(N(x, y)) \\
= & \varphi\left(\psi\left(\max \left\{d(g x, g y), d(g x, T x), d(g y, T y), \frac{d(g x, T y)+d(g y, T x)}{2 s}\right\}\right)\right) \\
& +L \psi(\min \{d(g x, T x), d(g y, T y), d(g x, T y), d(g y, T x)\}) \\
= & \varphi(\psi(d(T x, T y)))<\psi(d(T x, T y)) .
\end{aligned}
$$

Hence $d(T x, T y)=0$, that is, $y=T x=T y$. Therefore, $T y=g y=y$. Thus we proved that $T$ and $g$ have a common fixed point.

In the following, we deduce some fixed point theorems from our main results given by Theorems 2.1 and 2.2.

Corollary 2.3 Let $(X, d, \leq)$ be a partially ordered complete $b$-metric space and $T: X \rightarrow X$ is a nondecreasing mapping. Suppose there exist $\psi \in \Psi, \varphi \in \Phi$, and $L \geq 0$ such that

$$
\psi\left(s^{3} d(T x, T y)\right) \leq \varphi(\psi(M(x, y)))+L \psi(N(x, y))
$$

where

$$
M(x, y)=\max \left\{d(x, y), d(x, T x), d(y, T y), \frac{d(x, T y)+d(y, T x)}{2 s}\right\}
$$

and

$$
N(x, y)=\min \{d(x, T x), d(y, T y), d(x, T y), d(y, T x)\}
$$

for all $x, y \in X$ with $x \leq y$. Also suppose either

(a) if $\left\{x_{n}\right\} \subset X$ is a nondecreasing sequence with $x_{n} \rightarrow z$ in $X$, then $x_{n} \leq z$, for all $n$, holds, or

(b) $T$ is continuous.

If there exists $x_{0} \in X$ such that $x_{0} \leq T x_{0}$, then $T$ has a fixed point in $X$.

Example 2.1 Let $X$ be the set of Lebesgue measurable functions on $[0,1]$ such that $\int_{0}^{1}|x(t)| d t<\infty$. Define $D: X \times X \rightarrow[0, \infty)$ by

$$
D(x, y)=\left(\int_{0}^{1}|x(t)-y(t)| d t\right)^{2} .
$$


Then $D$ is a $b$-metric on $X$, with $s=2$. Also, this space can also be equipped with a partial order given by

$$
x, y \in X, \quad x \preceq y \quad \Longleftrightarrow x(t) \leq y(t) \quad \text { for any } t \in[a, b] .
$$

The operator $T: X \rightarrow X$ defined by

$$
T x(t)=t^{n}+e^{t}+\frac{\sqrt{2}}{4} \ln (|x(t)|+1) .
$$

Now, we prove that $T$ has a fixed point. For all $x, y \in X$ with $x \leq y$, we have

$$
\begin{aligned}
\sqrt{2^{3} D(T x, T y)} & =\sqrt{2^{3}\left(\int_{0}^{1}|T x(t)-T y(t)| d t\right)^{2}} \\
& \leq 2 \sqrt{2} \int_{0}^{1}\left|\frac{\sqrt{2}}{4} \ln (|x(t)|+1)-\frac{\sqrt{2}}{4} \ln (|y(t)|+1)\right| d t \\
& \leq \int_{0}^{1}|(\ln (|x(t)|+1)-\ln (|y(t)|+1))| d t \\
& \leq \int_{0}^{1} \ln \left(\frac{|x(t)|+1}{|y(t)|+1}\right) d t \\
& \leq \int_{0}^{1} \ln \left(1+\frac{|x(t)-y(t)|}{|y(t)|+1}\right) d t \\
& \leq \ln \left(1+\int_{0}^{1}|x(t)-y(t)| d t\right) \\
& \leq \ln \left(1+\sqrt{\left(\int_{0}^{1}|x(t)-y(t)| d t\right)^{2}}\right) \\
& \leq \ln (1+\sqrt{D(x, y)}) .
\end{aligned}
$$

Now, if we define $\varphi(t)=\ln (1+t), \psi(t)=\sqrt{t}$, and $x_{0}=0$. Thus, by Corollary 2.3 we see that $T$ has a fixed point.

Remark 2.1 Corollary 2.3 extends and generalizes many existing fixed point theorems in the literature $[2,3,51,52]$.

The following result is the immediate consequence of Corollary 2.3 .

Corollary 2.4 Let $(X, d, \leq)$ be a partially ordered complete b-metric space and $T: X \rightarrow X$ is a nondecreasing mapping. Suppose there exists $\varphi \in \Phi$ such that

$$
s^{3} d(T x, T y) \leq \varphi\left(\max \left\{d(x, y), d(x, T x), d(y, T y), \frac{d(x, T y)+d(y, T x)}{2 s}\right\}\right)
$$

for all $x, y \in X$ with $x \leq y$. Also suppose either

(a) if $\left\{x_{n}\right\} \subset X$ is a nondecreasing sequence with $x_{n} \rightarrow z$ in $X$, then $x_{n} \leq z$, for all $n$, holds, or 
(b) $T$ is continuous

If there exists $x_{0} \in X$ such that $x_{0} \leq T x_{0}$, then $T$ has a fixed point in $X$.

Remark 2.2 Corollary 2.4 is a generalization to [3, Theorem 1.3].

Taking $\varphi(t)=\lambda t, 0<\lambda<1$, in Corollary 2.4 we obtain the following generalization of the results in $[1,53]$.

Corollary 2.5 Let $(X, d, \leq)$ be a partially ordered complete $b$-metric space and $T: X \rightarrow X$ is a nondecreasing mapping. Suppose there exists $\varphi \in \Phi$ such that

$$
s^{3} d(T x, T y) \leq \lambda \max \left\{d(x, y), d(x, T x), d(y, T y), \frac{d(x, T y)+d(y, T x)}{2 s}\right\}
$$

for all $x, y \in X$ with $x \leq y$. Also suppose either

(a) if $\left\{x_{n}\right\} \subset X$ is a nondecreasing sequence with $x_{n} \rightarrow z$ in $X$, then $x_{n} \leq z$, for all $n$, holds, or

(b) $T$ is continuous.

If there exists $x_{0} \in X$ such that $x_{0} \leq T x_{0}$, then $T$ has a fixed point in $X$.

Corollary 2.6 Let $(X, d, \leq)$ be a partially ordered complete $b$-metric space and $T: X \rightarrow X$ is a nondecreasing mapping. Suppose there exist $\psi \in \Psi$ and $0 \leq \lambda<1$ such that

$$
\psi\left(s^{3} d(T x, T y)\right) \leq \lambda \psi(d(x, y))
$$

for all $x, y \in X$ with $x \leq y$. Also suppose either

(a) if $\left\{x_{n}\right\} \subset X$ is a nondecreasing sequence with $x_{n} \rightarrow z$ in $X$, then $x_{n} \leq z$, for all $n$, holds, or

(b) $T$ is continuous.

If there exists $x_{0} \in X$ such that $x_{0} \leq T x_{0}$, then $T$ has a fixed point in $X$.

\section{Application to integral equations}

Here, in this section, we wish to study the existence of a unique solution to a nonlinear quadratic integral equation, as an application to the our fixed point theorem. Consider the integral equation

$$
x(t)=h(t)+\lambda \int_{0}^{1} k(t, s) f(s, x(s)) d s, \quad t \in I=[0,1], \lambda \geq 0 .
$$

Let $\Gamma$ denote the class of those functions $\gamma:[0,+\infty) \rightarrow[0,+\infty)$ for which $\gamma \in \Phi$ and $(\gamma(t))^{p} \leq \gamma\left(t^{p}\right)$, for all $p \geq 1$.

For example, $\gamma_{1}(t)=k t$, where $0 \leq k<1$ and $\gamma_{2}(t)=\frac{t}{t+1}$ are in $\Gamma$.

We will analyze (3.1) under the following assumptions:

(a $) f: I \times \mathbb{R} \rightarrow \mathbb{R}$ is continuous monotone nondecreasing in $x, f(t, x) \geq 0$ and there exist constant $0 \leq L<1$ and $\gamma \in \Gamma$ such that for all $x, y \in \mathbb{R}$ and $x \geq y$

$$
|f(t, x)-f(t, y)| \leq L \gamma(x-y)
$$


$\left(\mathrm{a}_{2}\right) h: I \rightarrow \mathbb{R}$ is a continuous function.

(a) $k: I \times I \rightarrow \mathbb{R}$ is continuous in $t \in I$ for every $s \in I$ and measurable in $s \in I$ for all $t \in I$ such that

$$
\int_{0}^{1} k(t, s) d s \leq K
$$

and $k(t, s) \geq 0$.

$\left(a_{4}\right)$ There exists $\alpha \in C(I)$ such that

$$
\alpha(t) \leq h(t)+\lambda \int_{0}^{1} k(t, s) f(s, \alpha(s)) d s
$$

(a) $L^{p} \lambda^{p} K^{p} \leq \frac{1}{2^{3 p-3}}$.

We consider the space $X=C(I)$ of continuous functions defined on $I=[0,1]$ with the standard metric given by

$$
\rho(x, y)=\sup _{t \in I}|x(t)-y(t)| \quad \text { for } x, y \in C(I) .
$$

This space can also be equipped with a partial order given by

$$
x, y \in C(I), \quad x \leq y \quad \Longleftrightarrow \quad x(t) \leq y(t) \quad \text { for any } t \in I \text {. }
$$

Now for $p \geq 1$, we define

$$
d(x, y)=(\rho(x, y))^{p}=\left(\sup _{t \in I}|x(t)-y(t)|\right)^{p}=\sup _{t \in I}|x(t)-y(t)|^{p} \quad \text { for } x, y \in C(I) .
$$

It is easy to see that $(X, d)$ is a complete $b$-metric space with $s=2^{p-1}$ [44].

For any $x, y \in X$ and each $t \in I, \max \{x(t), y(t)\}$ and $\min \{x(t), y(t)\}$ belong to $X$ and are upper and lower bounds of $x, y$, respectively. Therefore, for every $x, y \in X$, one can take $\max \{x, y\}, \min \{x, y\} \in X$ which are comparable to $x, y$. Now, we formulate the main result of this section.

Theorem 3.1 Under assumptions $\left(\mathrm{a}_{1}\right)-\left(\mathrm{a}_{5}\right)$, (3.1) has a unique solution in $C(I)$.

Proof We consider the operator $T: X \rightarrow X$ defined by

$$
T(x)(t)=h(t)+\lambda \int_{0}^{1} k(t, s) f(s, x(s)) d s \quad \text { for } t \in I .
$$

By virtue of our assumptions, $T$ is well defined (this means that if $x \in X$ then $T(x) \in X$ ). For $x \leq y$, and $t \in I$ we have

$$
\begin{aligned}
T(x)(t)-T(y)(t) & =h(t)+\lambda \int_{0}^{1} k(t, s) f(s, x(s)) d s-h(t)-\lambda \int_{0}^{1} k(t, s) f(s, y(s)) d s \\
& =\lambda \int_{0}^{1} k(t, s)[f(s, x(s))-f(s, y(s))] d s \leq 0 .
\end{aligned}
$$


Therefore, $T$ has the monotone nondecreasing property. Also, for $x \leq y$, we have

$$
\begin{aligned}
|T(x)(t)-T(y)(t)| & =\left|h(t)+\lambda \int_{0}^{1} k(t, s) f(s, x(s)) d s-h(t)-\lambda \int_{0}^{1} k(t, s) f(s, y(s)) d s\right| \\
& \leq \lambda \int_{0}^{1} k(t, s)|f(s, x(s))-f(s, y(s))| d s \\
& \leq \lambda \int_{0}^{1} k(t, s) L \gamma(y(s)-x(s)) d s .
\end{aligned}
$$

Since the function $\gamma$ is nondecreasing and $x \leq y$, we have

$$
\gamma(y(s)-x(s)) \leq \gamma\left(\sup _{t \in I}|x(s)-y(s)|\right)=\gamma(\rho(x, y))
$$

hence

$$
|T(x)(t)-T(y)(t)| \leq \lambda \int_{0}^{1} k(t, s) L \gamma(\rho(x, y)) d s \leq \lambda K L \gamma(\rho(x, y)) .
$$

Then we obtain

$$
\begin{aligned}
d(T(x), T(y)) & =\sup _{t \in I}|T(x)(t)-T(y)(t)|^{p} \\
& \leq\{\lambda K L \gamma(\rho(x, y))\}^{p}=\lambda^{p} K^{p} L^{p} \gamma(\rho(x, y))^{p} \\
& \leq \lambda^{p} K^{p} L^{p} \gamma\left(\rho(x, y)^{p}\right)=\lambda^{p} K^{p} L^{p} \gamma(d(x, y)) \\
& \leq \lambda^{p} K^{p} L^{p} \varphi\left(\max \left\{d(x, y), d(x, T x), d(y, T y), \frac{d(x, T y)+d(y, T x)}{2 s}\right\}\right) \\
& \leq \frac{1}{2^{3 p-3}} \varphi\left(\max \left\{d(x, y), d(x, T x), d(y, T y), \frac{d(x, T y)+d(y, T x)}{2 s}\right\}\right) .
\end{aligned}
$$

This proves that the operator $T$ satisfies the contractive condition (2.21) appearing in Corollary 2.4. Also, let $\alpha, \beta$ be the functions appearing in assumption $\left(\mathrm{a}_{4}\right)$; then, by $\left(\mathrm{a}_{4}\right)$, we get $\alpha \leq T(\alpha)$. So, (3.1) has a solution and the proof is complete.

Example 3.1 Consider the following functional integral equation:

$$
x(t)=\frac{t^{2}}{1+t^{4}}+\frac{1}{27} \int_{0}^{1} \frac{e^{-s} \sin t}{2(1+t)} \frac{|x(s)|}{1+|x(s)|} d s
$$

for $t \in[0,1]$. Observe that this equation is a special case of (3.1) with

$$
\begin{aligned}
& h(t)=\frac{t^{2}}{1+t^{4}}, \\
& k(t, s)=\frac{e^{-s}}{1+t}, \\
& f(t, x)=\frac{\sin t}{2} \frac{|x|}{1+|x|} .
\end{aligned}
$$


Indeed, by using $\gamma(t)=\frac{1}{3} t$ we see that $\gamma \in \Phi$ and $(\gamma(t))^{p}=\left(\frac{1}{3} t\right)^{p}=\frac{1}{3^{p}} t^{p} \leq \frac{1}{3} t^{p}=\gamma\left(t^{p}\right)$, for all $p \geq 1$. Further, for arbitrarily fixed $x, y \in \mathbb{R}$ such that $x \geq y$ and for $t \in[0,1]$ we obtain

$$
\begin{aligned}
|f(t, x)-f(t, y)| & =\left|\frac{\sin t}{2} \frac{|x|}{1+|x|}-\frac{\sin t}{2} \frac{|y|}{1+|y|}\right| \\
& \leq \frac{1}{2}|x-y|=\frac{1}{6} \gamma(x-y) .
\end{aligned}
$$

Thus, the function $f$ satisfies assumption $\left(\mathrm{a}_{1}\right)$ with $L=\frac{1}{6}$. It is also easily seen that $h$ is a continuous function. Further, notice that the function $k$ is continuous in $t \in I$ for every $s \in I$ and measurable in $s \in I$ for all $t \in I$ and $k(t, s) \geq 0$. Moreover, we have

$$
\begin{aligned}
\int_{0}^{1} k(t, s) d s & =\int_{0}^{1} \frac{e^{-s}}{1+t} d s=\frac{1-e^{-1}}{1+t} \\
& \leq 1-e^{-1} \leq \frac{2}{3}=K
\end{aligned}
$$

If we put $\alpha(t)=\frac{3 t^{2}}{4\left(1+t^{4}\right)}$, we have

$$
\begin{aligned}
\alpha(t) & =\frac{3 t^{2}}{4\left(1+t^{4}\right)} \leq \frac{t^{2}}{1+t^{4}} \\
& \leq \frac{t^{2}}{1+t^{4}}+\frac{1}{27} \int_{0}^{1} \frac{e^{-s} \sin t}{2(1+t)} \frac{|\alpha(s)|}{1+|\alpha(s)|} d s \\
& =h(t)+\lambda \int_{0}^{1} k(t, s) f(s, \alpha(s)) d s .
\end{aligned}
$$

This shows that assumption $\left(\mathrm{a}_{4}\right)$ holds. Taking $L=\frac{1}{6}, K=\frac{2}{3}$ and $\lambda=\frac{1}{27}$, then inequality $L^{p} \lambda^{p} K^{p} \leq \frac{1}{2^{3 p-3}}$ appearing in assumption $\left(\mathrm{a}_{5}\right)$ has the following form:

$$
\frac{1}{6^{p}} \times \frac{1}{27^{p}} \times \frac{2^{p}}{3^{p}} \leq \frac{1}{2^{3 p-3}} .
$$

It is easily seen that each number $p \geq 1$ satisfies the above inequality. Consequently, all the conditions of Theorem 3.1 are satisfied. Hence the integral equation (3.2) has a unique solution in $C(I)$.

\section{Competing interests}

The authors declare that they have no competing interests.

\section{Authors' contributions}

All authors contributed equally to the writing of this paper. All authors read and approved the final manuscript.

\section{Author details}

'Department of Mathematics, Mashhad Branch, Islamic Azad University, Mashhad, Iran. ${ }^{2}$ Department of Mathematics, Sari Branch, Islamic Azad University, Sari, Iran. ${ }^{3}$ Department of Mathematics, Karaj Branch, Islamic Azad University, Alborz, Iran.

Received: 23 May 2014 Accepted: 5 September 2014 Published: 24 September 2014

\section{References}

1. Ran, ACM, Reurings, MCB: A fixed point theorem in partially ordered sets and some application to matrix equations. Proc. Am. Math. Soc. 132, 1435-1443 (2004) 
2. Nieto, JJ, Rodríguez-López, R: Contractive mapping theorems in partially ordered sets and applications to ordinary differential equations. Order 22, 223-239 (2005)

3. Agarwal, RP, El-Gebeily, MA, O'Regan, D: Generalized contractions in partially ordered metric spaces. Appl. Anal. 87(1), 109-116 (2008)

4. Altun, I, Durmaz, G: Some fixed point theorems on ordered cone metric spaces. Rend. Circ. Mat. Palermo 58, 319-325 (2009)

5. Beg, l, Rashid Butt, A: Fixed point for set-valued mappings satisfying an implicit relation in partially ordered metric spaces. Nonlinear Anal. 71, 3699-3704 (2009)

6. Ćirić, L, Cakić, N, Rajović, M, Ume, JS: Monotone generalized nonlinear contractions in partially ordered metric spaces. Fixed Point Theory Appl. 2008, Article ID 131294 (2008)

7. Grana Bhaskar, T, Lakshmikantham, V: Fixed point theorems in partially ordered metric spaces and applications. Nonlinear Anal. 65, 1379-1393 (2006)

8. Harjani, J, Sadarangani, K: Fixed point theorems for weakly contractive mappings in partially ordered sets. Nonlinear Anal. 71, 3402-3410 (2009)

9. Berinde, V: Approximating fixed points of weak contractions using the Picard iteration. Nonlinear Anal. Forum 9 43-53 (2004)

10. Berinde, V: Some remarks on a fixed point theorem for Ćirić-type almost contractions. Carpath. J. Math. 25, 157-162 (2009)

11. Berinde, $\mathrm{V}$ : Common fixed points of noncommuting almost contractions in cone metric spaces. Math. Commun. 15, 229-241 (2010)

12. Berinde, $\mathrm{V}$ : Approximating common fixed points of noncommuting almost contractions in metric spaces. Fixed Point Theory 11, 179-188 (2010)

13. Hussain, N, Đorić, D, Kadelburg, Z, Radenović, S: Suzuki-type fixed point results in metric type spaces. Fixed Point Theory Appl. 2012, 126 (2012)

14. Jovanović, M, Kadelburg, Z, Radenović, S: Common fixed point results in metric-type spaces. Fixed Point Theory Appl. 2010, Article ID 978121 (2010)

15. Pacurar, M: Fixed point theory for cyclic Berinde operators. Fixed Point Theory 11, 419-428 (2012)

16. Radenović, S, Kadelburg, Z: Quasi-contractions on symmetric and cone symmetric spaces. Banach J. Math. Anal. 5(1), 38-50 (2011)

17. Radenović, S, Kadelburg, Z, Jandrlić, D, Jandrlić, A: Some results on weakly contractive maps. Bull. Iran. Math. Soc. 38(3), 625-645 (2012)

18. Shah, MH, Simić, S, Hussain, N, Sretenović, A, Radenović, S: Common fixed points theorems for occasionally weakly compatible pairs on cone metric type spaces. J. Comput. Anal. Appl. 14(2), 290-297 (2012)

19. Shukla, S: Partial rectangular metric spaces and fixed point theorems. Sci. World J. 2014, Article ID 756298 (2014)

20. Suzuki, T: Fixed point theorems for Berinde mappings. Bull. Kyushu Inst. Technol., Pure Appl. Math. 58, 13-19 (2011)

21. Babu, GVR, Sandhya, ML, Kameswari, MVR: A note on a fixed point theorem of Berinde on weak contractions. Carpath. J. Math. 24, 8-12 (2008)

22. Ćirić, L, Abbas, M, Saadati, R, Hussain, N: Common fixed points of almost generalized contractive mappings in ordered metric spaces. Appl. Math. Comput. 217, 5784-5789 (2011)

23. Aghajani, A, Radenović, S, Roshan, JR: Common fixed point results for four mappings satisfying almost generalized $(S, T)$-contractive condition in partially ordered metric spaces. Appl. Math. Comput. 218, 5665-5670 (2012)

24. Czerwik, S: Contraction mappings in b-metric spaces. Acta Math. Inform. Univ. Ostrav. 1, 5-11 (1993)

25. Aghajani, A, Arab, R: Fixed points of $(\psi, \phi, \theta)$-contractive mappings in partially ordered $b$-metric spaces and application to quadratic integral equation. Fixed Point Theory Appl. 2013, 245 (2013)

26. Azam, A, Mehmood, N, Ahmad, J, Radenović, S: Multivalued fixed point theorems in cone b-metric spaces. J. Inequal. Appl. 2013, $582(2013)$

27. Boriceanu, M: Fixed point theory for multivalued generalized contraction on a set with two $b$-metrics. Stud. Univ. Babeş-Bolyai, Math. LIV(3), 3-14 (2009)

28. Boriceanu, M: Strict fixed point theorems for multivalued operators in b-metric spaces. Int. J. Mod. Math. 4(3), 285-301 (2009)

29. George, R, Radenović, S, Reshma, KP, Shukla, S: Rectangular b-metric spaces and contraction principle. J. Nonlinear Sci. Appl. (2014, in press)

30. Hussain, N, Parvaneh, $V$, Roshan, JR, Kadelburg, Z: Fixed points of cyclic $(\psi, \varphi, L, A, B)$-contractive mappings in ordered b-metric spaces with applications. Fixed Point Theory Appl. 2013, 256 (2013)

31. Mustafa, Z, Roshan, JR, Parvaneh, V: Coupled coincidence point results for $(\psi, \varphi)$-weakly contractive mappings in partially ordered $G_{b}$-metric spaces. Fixed Point Theory Appl. 2013, 206 (2013)

32. Mustafa, Z, Roshan, JR, Parvaneh, V, Kadelburg, Z: Some common fixed point results in ordered partial $b$-metric spaces. J. Inequal. Appl. 2013, 562 (2013)

33. Popović, B, Radenović, S, Shukla, S: Fixed point results to TVS-cone b-metric spaces. Gulf J. Math. 1, 51-64 (2013)

34. Roshan, JR, Shobkolaei, N, Sedhi, S, Parvaneh, V, Radenović, S: Common fixed point theorems for three maps in discontinuous $G_{b}$-metric spaces. Acta Math. Sci. Ser. B 34(5), 1-12 (2014)

35. Shukla, S: Partial b-metric spaces and fixed point theorems. Mediterr. J. Math. 11, 703-711 (2014)

36. Zabihi, F, Razani, A: Fixed point theorems for hybrid rational Geraghty contractive mappings in ordered $b$-metric spaces. J. Appl. Math. 2014, Article ID 929821 (2014)

37. Roshan, JR, Parvaneh, $V$, Altun, I: Some coincidence point results in ordered $b$-metric spaces and applications in a system of integral equations. Appl. Math. Comput. 226, 725-737 (2014)

38. Roshan, JR, Parvaneh, V, Kadelburg, Z: Common fixed point theorems for weakly isotone increasing mappings in ordered b-metric spaces. J. Nonlinear Sci. Appl. (to appear). www.tjnsa.com

39. Roshan, JR, Parvaneh, V, Sedghi, S, Shobkolaei, N, Shatanawi, W: Common fixed points of almost generalized $(\psi, \varphi)_{s}$-contractive mappings in ordered b-metric spaces. Fixed Point Theory Appl. 2013, 159 (2013)

40. Singh, SL, Prasad, B: Some coincidence theorems and stability of iterative procedures. Comput. Math. Appl. 55 2512-2520 (2008) 
41. Pacurar, M: Sequences of almost contractions and fixed points in b-metric spaces. An. Univ. Vest. Timiş., Ser. Mat.-Inform. 48, 125-137 (2010)

42. Hussain, N, Shah, MH: KKM mappings in cone b-metric spaces. Comput. Math. Appl. 62, 1677-1684 (2011)

43. Czerwik, S: Nonlinear set-valued contraction mappings in b-metric spaces. Atti Semin. Mat. Fis. Univ. Modena 46(2), 263-276 (1998)

44. Aghajani, A, Abbas, M, Roshan, JR: Common fixed point of generalized weak contractive mappings in partially ordered $b$-metric spaces. Math. Slovaca (in press)

45. Khamsi, MA, Hussain, N: KKM mappings in metric type spaces. Nonlinear Anal. 73(9), 3123-3129 (2010)

46. Đukić, D, Kadelburg, Z, Radenović, S: Fixed points of Geraghty-type mappings in various generalized metric spaces. Abstr. Appl. Anal. 2011, Article ID 561245 (2011)

47. Parvaneh, $\mathrm{V}$, Roshan, JR, Radenović, S: Existence of tripled coincidence point in ordered b-metric spaces and application to a system of integral equations. Fixed Point Theory Appl. 2013, 130 (2013)

48. Radenović, S, Kadelburg, Z: Generalized weak contractions in partially ordered metric spaces. Comput. Math. Appl. 60, 1776-1783 (2010)

49. An, TV, Dung, NV, Kadelburg, Z, Radenović, S: Various generalizations of metric spaces and fixed point theorems. Rev. R. Acad. Cienc. Exactas Fís. Nat., Ser. A Mat. (2014). doi:10.1007/s13398-014-0173-7

50. Khamsi, MA: Remarks on cone metric spaces and fixed point theorems of contractive mappings. Fixed Point Theory Appl. 2010, Article ID 315398 (2010). doi:10.1155/2010/315398

51. Altman, M: A fixed point theorem in compact metric spaces. Am. Math. Mon. 82, 827-829 (1975)

52. Khan, MS, Swaleh, M, Sessa, S: Fixed point theorems by altering distances between the points. Bull. Aust. Math. Soc. 30, 1-9 (1984)

53. Ray, BK: On Ciric's fixed point theorem. Fundam. Math. 94(3), 221-229 (1977)

doi:10.1186/1029-242X-2014-355

Cite this article as: Allahyari et al.: A generalization on weak contractions in partially ordered $b$-metric spaces and its application to quadratic integral equations. Journal of Inequalities and Applications 2014 2014:355.

\section{Submit your manuscript to a SpringerOpen ${ }^{\ominus}$ journal and benefit from:}

- Convenient online submission

- Rigorous peer review

Immediate publication on acceptance

Open access: articles freely available online

High visibility within the field

- Retaining the copyright to your article 